\title{
Zinc, copper and manganese in the alimentary tract of sheep
}

\author{
BY I. BREMNER \\ Rowett Research Institute, Bucksburn, Aberdeen $A B 2{ }_{9} S B$
}

(Received 18 December 1969-Accepted 31 March 1970)

\begin{abstract}
I. The changes in the concentrations and solubilities of zinc, manganese and copper in the rumen, abomasum and along the small intestine of cannulated sheep, maintained on dried grass, have been determined. Relationships between the solubilities of the metals and the $\mathrm{pH}$ values of the samples were observed.

3. The pattern of change of solubilities could be reproduced in vitro by adjustment of the $\mathrm{pH}$ of rumen and abomasal samples.

3. By a combination of gel filtration and continuous-flow high-voltage electrophoretic techniques it was shown that soluble complexes of $\mathrm{Zn}$ and $\mathrm{Mn}$ occur in the rumen and lower regions of the small intestine. The soluble $\mathrm{Zn}$ and $\mathrm{Mn}$ in the abomasum, duodenum and upper jejunum appeared to exist in ionic form. The charge and molecular size of these complexes were found to be dependent on the $\mathrm{pH}$ of the samples.

4. From detergent treatment of rumen samples it appeared that much of the insoluble metal, particularly $\mathrm{Cu}$, might be associated with microbial matter.

5. The significance of these findings and their relationship to the differences noted in the apparent requirements for trace elements of ruminants on different diets is discussed.
\end{abstract}

It has often been found in investigations into the mechanisms controlling the intestinal absorption of trace metals that uptake and transport of the metals occur preferentially in certain segments of the alimentary tract (Van Campen \& Mitchell, I965) and can be influenced by the administration of suitable chelating agents (Saltman, 1965). It has been claimed that the apparent differences in the absorptive capacity of the different regions of the small intestine are related to the $\mathrm{pH}$ (and therefore to the solubilities of the metals) in the gut lumen (Kroe, Kaufman, Klavins \& Kinney, 1966). The action of orally administered chelating agents in modifying the pattern of trace-metal metabolism is not fully understood, but in addition to causing an increase in the solubility of the metals in the gut lumen they may be involved in the transport of trace metals in complexed forms into the blood. In this paper the term 'metal complex' is used to denote the substance formed when the water molecules surrounding a metal ion are replaced by other molecules or ions. Simple hydroxo complexes are excluded from this definition. The group that combines with the metal ion is called a 'ligand'.

Few attempts have been made to establish the forms in which metals can exist in the alimentary tract or the changes which occur on passage of the digesta along the tract. Storry (I96I) has noted the variations in the ultrafiltrability of calcium and magnesium in the alimentary tract of sheep, and has shown that for Ca some of these variations are related to the gradient of $\mathrm{pH}$ which occurs along the tract. Bosman (1964) has suggested that copper sulphide may be present in rumen samples and that copper-porphyrin complexes may exist in the faeces of cattle fed on fresh grass. It has recently been postulated (Dowdy \& Matrone, I968 $a, b$ ) that the dietary interaction 
between $\mathrm{Cu}$ and molybdenum may result from the formation of an insoluble nonavailable complex between them.

Previous studies (Bremner \& Knight, 1970) on the characterization of the complexes of trace elements present in ryegrass have shown that over $60 \%$ of the $\mathrm{Zn}$, Mn and $\mathrm{Cu}$ are readily extracted with aqueous ethanol and water. $\mathrm{Mn}$ was shown to exist in these extracts in cationic, probably non-complexed form, but the $\mathrm{Zn}$ and $\mathrm{Cu}$ were present in the form of a series of closely related anionic complexes of low molecular weight whose behaviour was to a large extent dependent on $\mathrm{pH}$. On the basis of further extraction and enzymic treatments, a large proportion of the residual $\mathrm{Zn}$ appeared to be associated with protein and polysaccharide material. It was suggested that over $85 \%$ of the $\mathrm{Zn}$ in the plant could be in soluble form in the stomach as a combined result of the acid environment and of proteolytic digestion.

In the present paper the results are reported of a similar investigation into the nature of the binding of $\mathrm{Zn}, \mathrm{Cu}$ and $\mathrm{Mn}$ in the alimentary tract of sheep maintained on dried grass. The solubilities of the metals along the tract were found to be largely dependent on the $\mathrm{pH}$ of the samples. Evidence was found for the existence of soluble, complexed forms of $\mathrm{Zn}$ and $\mathrm{Mn}$ only in the rumen and in the lower regions of the small intestine. The properties of these complexes, both in terms of molecular size and charge, varied greatly along the alimentary tract.

\section{EXPERIMENTAL}

Animals. Four Scottish Blackface, one Romney Cross and one Suffolk Cross sheep, each weighing $30-40 \mathrm{~kg}$, were used. They were fitted with various combinations of simple cannulas (in the rumen and abomasum) and re-entrant cannulas (in the duodenum, in various regions of the jejunum and in the terminal ileum). Details of the surgical procedures, which had generally been carried out several months before the samples of digesta were collected, have been published previously (cf. Topps, Kay \& Goodall, 1968). The animals were housed indoors in a 'trace-element-free' environment.

Diets. The animals were maintained on a diet of dried grass (two meals/d each of $400 \mathrm{~g}$ ) and were given de-ionized water to drink.

Sampling. Samples $(30-100 \mathrm{ml})$ of intestinal contents were collected from the appropriate cannulas, usually about $2 \mathrm{~h}$ after the morning feed. Suitable portions were retained for analysis for dry matter (DM) and trace elements. A weighed quantity (about $3 \circ \mathrm{g}$ ) of the remainder was centrifuged immediately at $38000 \mathrm{~g}$ for $\mathrm{I} \mathrm{h}$ and the supernatant liquid was collected. This liquid was then sampled for DM content, $\mathrm{pH}$ and trace-element content. Samples of ileal contents were generally diluted $I: r(v / v)$ with water before analysis.

Chemical analyses. Analyses for trace metals were carried out on acid digests of all samples by atomic absorption spectroscopy, using a Hilger-Watt AA2 Spectrophotometer.

In vitro $p H$ adjustment of rumen and abomasal samples. Samples of rumen and abomasal contents were collected and slowly titrated, with vigorous stirring, with 
$5 \mathrm{~N}-\mathrm{HCl}$ or $\mathrm{NaOH}$ respectively to give a series of mixtures with $\mathrm{pH}$ values ranging from around 6.5 to 2 and from 3 to 10 . These samples were fractionated by centrifugation at $38000 \mathrm{~g}$ for $30 \mathrm{~min}$ as above and the solubilities of the $\mathrm{Zn}, \mathrm{Mn}$ and $\mathrm{Cu}$ related to the $\mathrm{pH}$ of the sample.

Similar adjustment of the $\mathrm{pH}$ of the supernatant fractions of abomasal samples was made by the addition of $2 \mathrm{~N}-\mathrm{NaOH}$. The mixtures were then centrifuged again at $38000 \mathrm{~g}$ and the trace-element concentrations of the supernatant liquids determined. Corrections were always made for the small amount of trace metals contained in the $\mathrm{NaOH}$.

Detergent treatment of dried grass and of insoluble residues of gut samples. A sample ( $\mathrm{g}$ DM) of the insoluble residue collected after centrifugation of a rumen sample was extracted with $3 \%(\mathrm{w} / \mathrm{v})$ sodium dodecyl sulphate (SDS) in $0.02 \mathrm{M}$-tris-maleate buffer, $\mathrm{pH} 6.5(\mathrm{roO} \mathrm{ml})$ at $100^{\circ}$ for $\mathrm{I} \mathrm{h}$. The mixture was cooled and filtered through acid-washed Whatman no. 4I filter-paper. The residues and portions of the filtrate were digested with acid and analysed for trace metals.

Samples $(4 \times 500 \mathrm{mg})$ of milled dried grass were extracted twice with distilled water $(3 \circ \mathrm{ml})$ for $24 \mathrm{~h}$ each time. The mixtures were centrifuged, and portions of the supernatant liquids and of two of the residual fractions were digested and analysed for trace metals. The other residual fractions were then extracted with SDS as above.

The insoluble residues collected from abomasal samples were similarly extracted with $(a) \operatorname{SDS}(3 \%, \mathrm{w} / \mathrm{v})$ in sodium formate buffer $\left(0 \cdot \mathrm{I}, \mathrm{pH}_{3} \cdot 0\right)$ and $(b)$ cetyl trimethylammonium bromide $(3 \%, \mathrm{w} / \mathrm{v})$ in sodium formate buffer $\left(\mathrm{O}^{\circ} \mathrm{IM}, \mathrm{pH} 3^{\circ} \mathrm{O}\right)$.

Gel filtration. Separations were carried out on columns, usually $850 \times 25 \mathrm{~mm}$ or $450 \times 25 \mathrm{~mm}$, of Sephadex G-100 (Pharmacia Ltd, Uppsala, Sweden) or of Biogel P-2 (Biorad Laboratories Ltd, Richmond, California). The columns were pre-equilibrated with the chloroform-saturated buffer $(0.02 \mathrm{M})$ used as eluant for the particular separation. All the buffers were purified before use by extraction with $0.2 \%$ diphenylthiocarbazone in $\mathrm{CCl}_{4}$ or by passage through a column of Chelex-100 (Biorad Laboratories Ltd). The choice of buffer was determined by the $\mathrm{pH}$ of the sample. The following buffers were used: formic acid-sodium hydroxide, acetic acid-sodium hydroxide, tris-maleic acid-sodium hydroxide, tris-acetic acid. Columns were washed with $\mathrm{O} \cdot \mathrm{I} \mathrm{N}-\mathrm{HCl}$ between separations to remove adsorbed metal. Samples were applied directly to the columns after centrifugation of the gut contents. Fractions (5 or Io $\mathrm{ml}$ ) were collected automatically and analysed directly for metals by atomic absorption spectroscopy.

Continuous-flow high-voltage electrophoresis. The soluble fractions obtained by centrifugation of gut samples were separated electrophoretically on the continuousflow electrophoresis apparatus of Hannig (Elphor VaP r; Drs Bender and Hobein Grubh, Munich, Germany). Choice and treatment of all buffers was as detailed above. The buffer concentrations and operating conditions used were as detailed in Table I. The operating conditions were adjusted so that the contaminant metal present (see Bremner \& Knight, 1970) did not coincide with any of the major metal-containing fractions. The fractions collected were analysed for metals by atomic absorption spectroscopy, either directly or after suitable concentration. 


\section{RESULTS}

\section{Concentration and solubilities of metals in gut samples}

In Table 2 the mean $\mathrm{pH}$ values and mean concentrations are given of $\mathrm{Zn}, \mathrm{Cu}$ and $\mathrm{Mn}$ in samples collected at cannulas situated in the rumen and along the small intestine of several sheep fed twice daily on dried grass. The trace-element composition

Table I. Details of buffers and operating conditions in continuous-flow high-voltage electrophoresis

$\begin{array}{ccccccc}\begin{array}{c}\text { Composition } \\ \text { of buffer }\end{array} & \mathrm{pH} & \overbrace{\begin{array}{c}\text { Electrode } \\ \text { chamber }\end{array}}^{\text {Concentration (M) }} & \text { Cuvette } & \begin{array}{c}\text { Buffer flow- } \\ \text { cuvette } \\ (\mathrm{m} 1 / \mathrm{h})\end{array} & \begin{array}{c}\text { Voltage } \\ (\mathrm{V})\end{array} & \begin{array}{c}\text { Current } \\ (\mathrm{mA})\end{array} \\ \begin{array}{c}\text { Formic acid-sodium } \\ \text { hydroxide }\end{array} & 3.0 & 0.2 & 0.01 & 145 & 2100 & 150 \\ \begin{array}{c}\text { Formic acid-sodium } \\ \text { hydroxide }\end{array} & 3.6 & 0.2 & 0.02 & 150 & 1400 & 150 \\ \begin{array}{c}\text { Acetic acid-sodium } \\ \text { hydroxide }\end{array} & 4.9 & 0.2 & 0.03 & 170 & 1500 & 160 \\ \begin{array}{c}\text { Tris-maleic acid- } \\ \text { sodium hydroxide }\end{array} & 6.5 & 0.2 & 0.01 & 150 & 2000 & 150 \\ \begin{array}{c}\text { Tris-acetic acid } \\ \text { Tris-a }\end{array} & 8.2 & 0.2 & 0.04 & 150 & 2100 & 80\end{array}$

Table 2. Mean total $\mathrm{Zn}, \mathrm{Mn}$ and $\mathrm{Cu}$ concentrations and $p H$ of samples collected from rumen, abomasum and small intestine of sheep maintained on dried grass

\begin{tabular}{|c|c|c|c|c|}
\hline \multirow[b]{2}{*}{ Source of sample } & \multirow[b]{2}{*}{$\mathrm{pH}$} & \multicolumn{3}{|c|}{ Concentration $(\mu \mathrm{g} / \mathrm{g}$ DM) } \\
\hline & & $\mathrm{Zn}$ & $\mathrm{Mn}$ & $\mathrm{Cu}$ \\
\hline Rumen* & $6 \cdot 5$ & $\begin{array}{c}68 \pm 16 \\
(8)\end{array}$ & $\begin{array}{c}88 \pm 19 \\
(8)\end{array}$ & $9 \cdot 7 \pm x+9$ \\
\hline Abomasum* & $3 \cdot 0$ & $\frac{66 \pm 14}{(8)}$ & $\begin{array}{c}\text { I } 10 \pm 10 \\
(8)\end{array}$ & $\stackrel{13 \pm I}{(8)}$ \\
\hline Duodenum & $3 \cdot 0$ & $\begin{array}{l}75 \\
(2)\end{array}$ & $\begin{array}{l}94 \\
(2)\end{array}$ & $\begin{array}{l}15 \\
(2)\end{array}$ \\
\hline Mid-jejunum & 4.9 & $\begin{array}{r}109 \\
(3)\end{array}$ & $\begin{array}{r}162 \\
(3)\end{array}$ & $\begin{array}{l}18 \\
(3)\end{array}$ \\
\hline Lower jejunum & $7 \cdot 4$ & $\begin{array}{r}134 \\
(3)\end{array}$ & $\begin{array}{r}\text { 191 } \\
(3)\end{array}$ & $\begin{array}{r}18 \\
(3)\end{array}$ \\
\hline Ileum* & $8 \cdot 2$ & $95 \frac{20}{(7)}$ & $216 \pm \frac{49}{(7)}$ & $\frac{22 \pm 4}{(7)}$ \\
\hline
\end{tabular}

Figures in parentheses are the numbers of samples.

* Mean values and standard deviations.

of the grass varied slightly throughout the experimental period but the concentrations of $\mathrm{Zn}, \mathrm{Mn}$ and $\mathrm{Cu}$ were about 40,60 and $6 \mu \mathrm{g} / \mathrm{g}$ DM respectively. When expressed in terms of DM content the concentrations of the three metals in all gut samples were greater than in the dried grass. There was a gradual increase in the concentrations of all metals on passage of the digesta from the rumen to the terminal ileum. 
Vol. 24

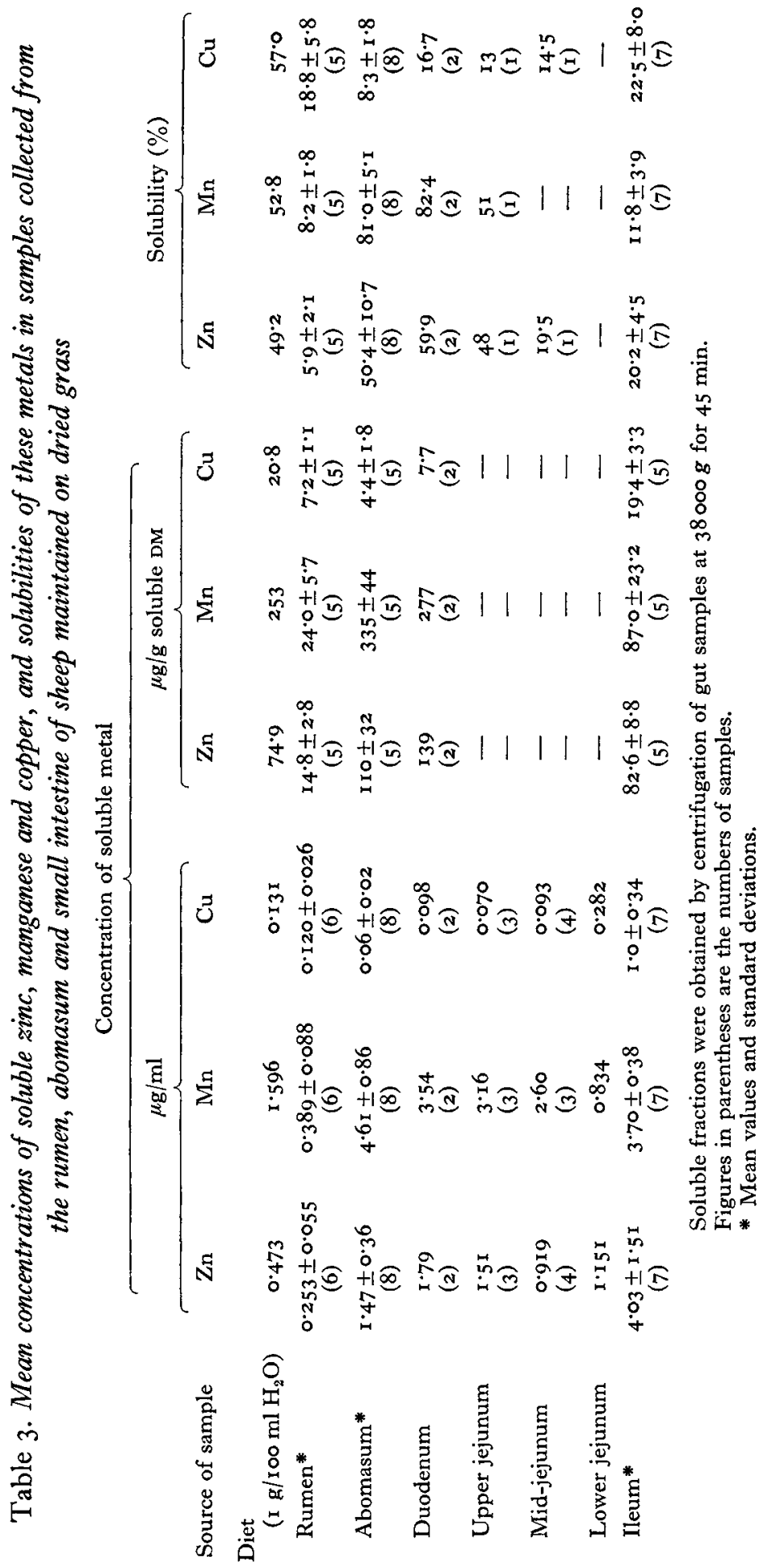


The mean concentrations of $\mathrm{Zn}, \mathrm{Mn}$ and $\mathrm{Cu}$ in the supernatant fractions obtained by centrifugation of the gut samples at $38000 \mathrm{~g}$ are given in Table 3 . In rumen samples the concentrations of all three metals in the soluble dry matter $(\mu \mathrm{g} / \mathrm{g} \mathrm{DM})$ were very low compared with the concentrations in aqueous extracts of the dried grass. On

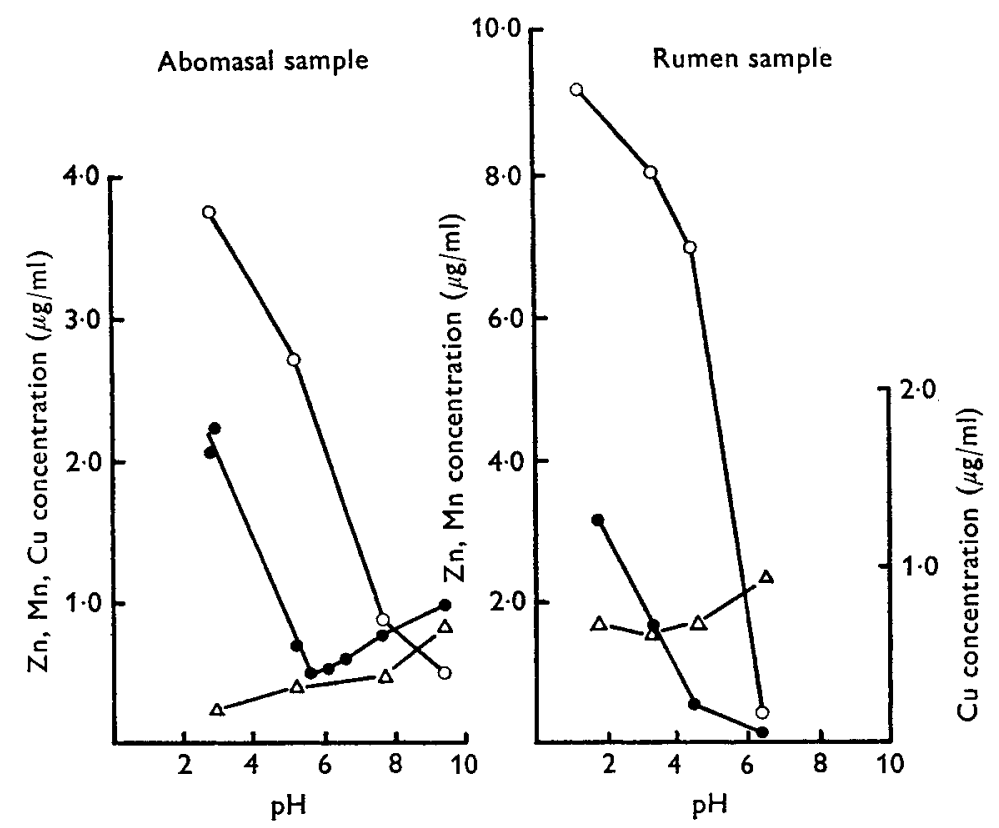

Fig. I. Effect of $\mathrm{pH}$ adjustment on the solubilities of zinc $(\odot)$, manganese $(O)$ and copper $(\triangle)$ in unfractionated samples of abomasal and rumen contents of sheep maintained on dried grass.

Table 4. Extraction with detergent of insoluble residues from rumen and abomasum of sheep maintained on dried grass

\begin{tabular}{|c|c|c|c|c|c|c|c|c|c|c|}
\hline \multirow{2}{*}{$\begin{array}{c}\text { Source of } \\
\text { sample }\end{array}$} & \multirow[b]{2}{*}{ Treatment } & \multicolumn{3}{|c|}{$\begin{array}{c}\text { Metal in soluble } \\
\text { form in original } \\
\text { supernatant liquid } \\
(\%)\end{array}$} & \multicolumn{3}{|c|}{$\begin{array}{c}\text { Metal extracted } \\
\text { with detergent } \\
(\%)\end{array}$} & \multicolumn{3}{|c|}{$\begin{array}{c}\text { Metal insoluble } \\
\text { after extraction } \\
\text { with detergent } \\
(\%)\end{array}$} \\
\hline & & $\mathrm{Zn}$ & Mn & $\mathrm{Cu}$ & $\mathbf{Z}_{\mathbf{n}}$ & $\mathrm{Mn}$ & $\mathrm{Cu}$ & $Z_{n}$ & $\mathrm{Mn}$ & $\mathrm{Cu}$ \\
\hline Rumen & SDS, pH 6.5 & 5 & 5 & 20 & 63 & 20 & 77 & 32 & 75 & 3 \\
\hline Abomasum & $\mathrm{SDS}, \mathrm{pH} 3 \cdot 0$ & 66 & 83 & 7 & I8 & 14 & 52 & 16 & 3 & $4 \mathrm{I}$ \\
\hline Abomasum & CETAB, pH 3.0 & 66 & 83 & 7 & 28 & 16 & 55 & 6 & $\mathbf{I}$ & 38 \\
\hline
\end{tabular}

SDS, sodium dodecyl sulphate; CETAB, cetyltrimethylammonium bromide.

All results were calculated as percentages of the metals present in the original sample.

passage of the digesta into the abomasum, where the $\mathrm{pH}$ was generally around $3 \cdot 0$, there was a very large increase in the soluble concentrations of $\mathrm{Zn}$ and $\mathrm{Mn}$. In some abomasal samples the $\mathrm{pH}$ was abnormally high, $4^{\cdot 0}-4^{\cdot} 6$, and in these samples only a twofold increase in the soluble concentrations of these metals occurred. The variations in the concentrations of soluble $\mathrm{Cu}$ along the gut were less pronounced, but it appeared 
that the lowest concentrations were found in the abomasum and upper small intestine and the highest in the ileum. The mean concentrations of soluble $\mathrm{Cu}$ in the abomasum were, surprisingly, less than in the rumen and less than in an aqueous extract of the grass. Calculation of the percentage solubilities of the metals in the gut samples revealed a similar dependence on $\mathrm{pH}$ (Table 3 ).

These patterns of changes in the solubilities of $\mathrm{Zn}, \mathrm{Mn}$ and $\mathrm{Cu}$ with the variation in the $\mathrm{pH}$ of the samples could be reproduced in vitro by adjustment of the $\mathrm{pH}$ of both rumen and abomasal samples (Fig. I). When the $\mathrm{pH}$ adjustment was carried out on the supernatant fraction of the abomasal sample, it was found that the decreases in the concentrations of soluble $\mathrm{Zn}$ and $\mathrm{Mn}$ were almost identical with those found for the abomasal sample whose $\mathrm{pH}$ was adjusted before centrifugation, but that the concentration of soluble $\mathrm{Cu}$ decreased by about half as the $\mathrm{pH}$ was raised to around 8 . As the $\mathrm{pH}$ was increased above 6 , it was found that the concentration of soluble $\mathrm{Zn}$ increased only very slightly, in contrast to the changes noted in Fig. I.

The results of the treatment with detergent (Mason, 1969) of the insoluble residues obtained from rumen and abomasal samples are shown in Table 4 . It can be seen that after extraction of the rumen samples with SDS at $\mathrm{pH} 6.5$ practically all the residual $\mathrm{Cu}$ was liberated but that 32 and $75 \%$ of the total $\mathrm{Zn}$ and $\mathrm{Mn}$ respectively were still insoluble. In abomasal samples, however, almost complete liberation of the $\mathrm{Zn}$ and $\mathrm{Mn}$ from the insoluble residues resulted from extractions at $\mathrm{pH}_{3} \cdot{ }^{\circ}$, with either SDS or cetyltrimethylammonium bromide, whereas around $40 \%$ of the original $\mathrm{Cu}$ was still insoluble.

Extraction of the water-insoluble residues of dried grass with SDS at $\mathrm{pH} 6.5$ did not liberate significant amounts of the trace metals.

\section{Gel filtration studies}

Examination by gel filtration of the supernatant fractions, collected after centrifugation of samples from the gastro-intestinal tract, provided valuable information on the association of $\mathrm{Zn}$ and of $\mathrm{Mn}$ with other components in the tract. Separation on Biogel P-2 of samples from the abomasum and upper jejunum at $\mathrm{pH}_{3} \cdot \circ$ and 3.6 respectively revealed the presence of single $\mathrm{Zn}$ and $\mathrm{Mn}$ components in both samples, with elution volumes similar to those observed for the ionic forms of the metals (Fig. 2).

Similar examination of a sample collected from the mid-jejunal region ( $\mathrm{pH}_{4} \cdot 9$ ), however, showed the presence of two major $\mathrm{Zn}$ complexes of low molecular weight and not corresponding in elution volume to ionic $\mathrm{Zn}$ (Fig. 3). In addition, a minor $\mathrm{Zn}$ complex was detected which was excluded by the gel, which has an exclusion limit of about 2600 mol. wt.

Examination of an ileal sample on Sephadex G-roo, using tri-sacetate, $\mathrm{pH} 8 \cdot 2$, as eluant, revealed the presence of at least three $\mathrm{Zn}$ components (Fig. 4). The major complex contained about $60 \%$ of the total $\mathrm{Zn}$ and was excluded by the gel, which has a reported exclusion limit of $100000 \mathrm{~mol}$. wt. The other two complexes were of much lower molecular weight. The elution pattern for the $\mathrm{Zn}$ was not unlike that observed for the substances absorbing at $280 \mathrm{~nm}$. 


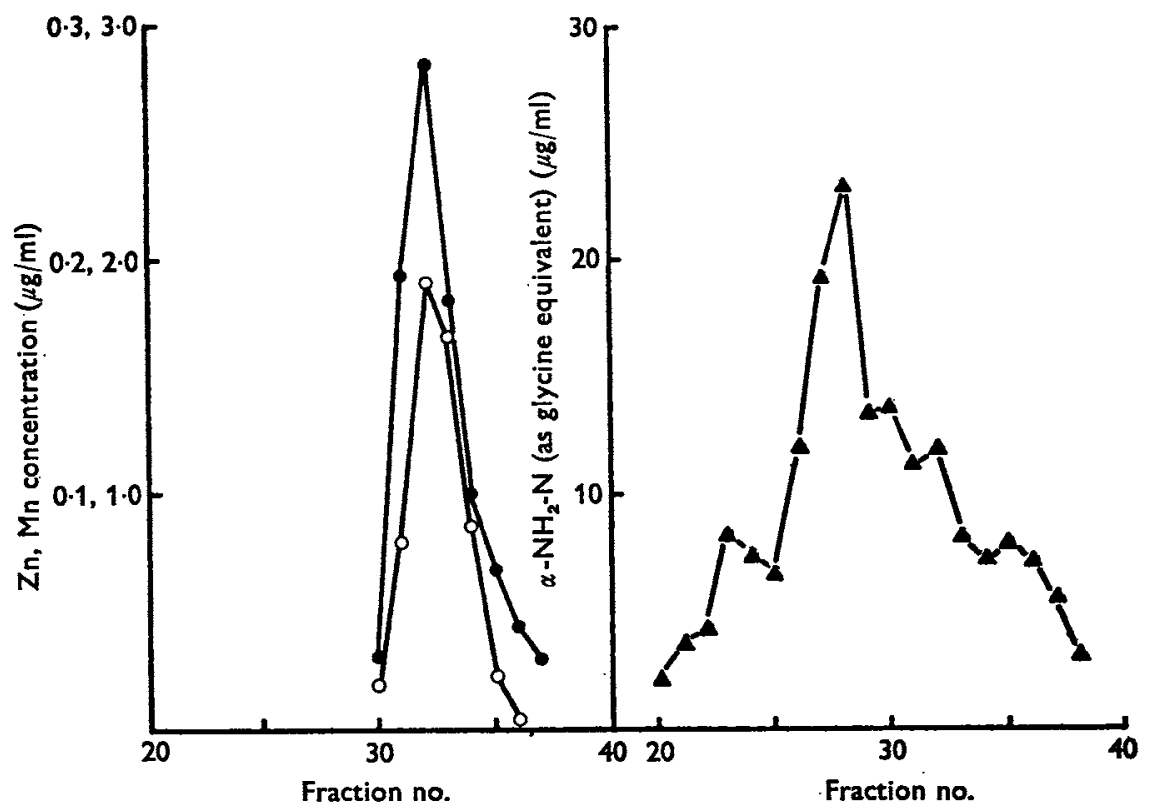

Fig. 2. Gel filtration on Biogel $P_{-2}$ of supernatant fraction of samples of abomasal contents from sheep maintained on dried grass. Concentrations of $\mathrm{Zn}(\mathbf{O}), \mathrm{Mn}(\mathrm{O})$ and $\alpha-\mathrm{NH}_{2}$ nitrogen (as glycine equivalent) $(\boldsymbol{A})$ are shown.

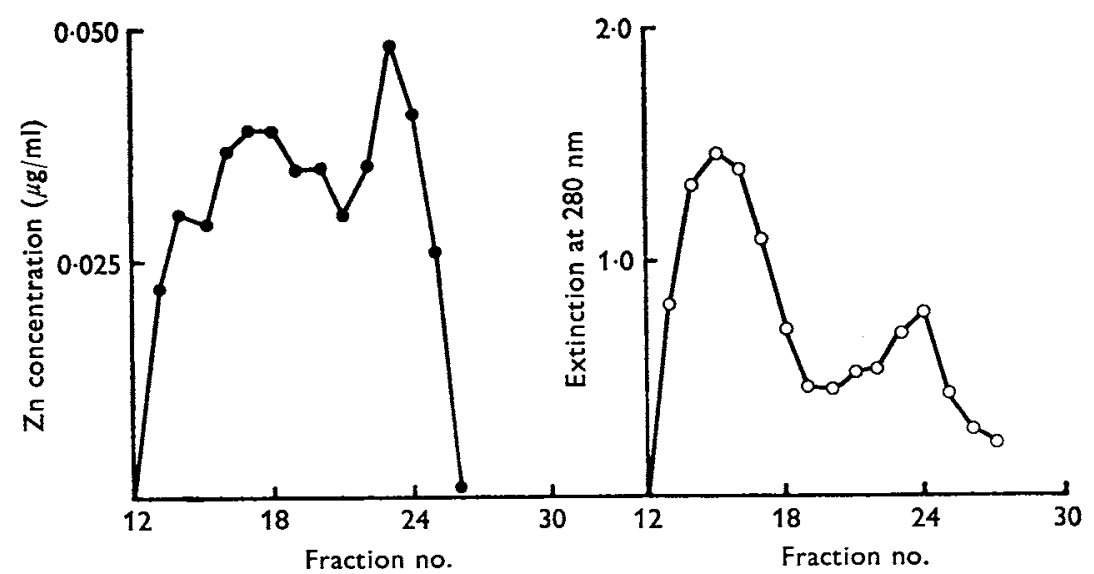

Fig. 3. Gel filtration on Biogel $\mathrm{P}-2$ at $\mathrm{pH}_{3} .6$ of supernatant fraction of sample collected from mid-jejunum of sheep maintained on dried grass. Concentration of $\mathrm{Zn}(\odot)$ and extinction at $280 \mathrm{~nm}(\mathrm{O})$ are shown.

\section{High-voltage electrophoresis studies}

Electrophoretic examination of the supernatant fractions of two rumen samples, collected before and after the morning feed, was made using tris-maleate buffer at $\mathrm{pH}$ 6.5. The trace-element compositions of the two samples were similar except that the concentration of soluble $\mathrm{Mn}$ in the prefeeding sample was only $45 \%$ that in the post-feeding sample. Two main $\mathrm{Zn}$ components were detected in both samples 
Vol. 24

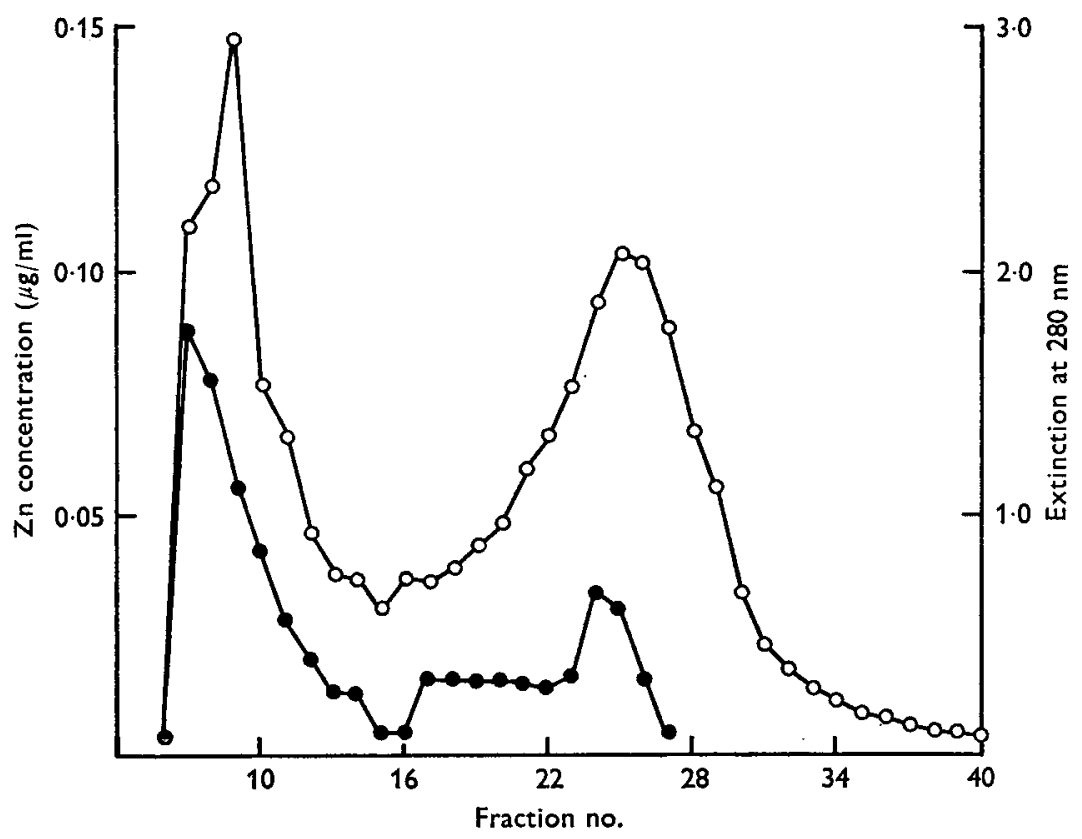

Fig. 4. Gel filtration on Sephadex G-roo at pH 8.2 of supernatant fraction of ileal sample from sheep maintained on dried grass. Concentration of $\mathrm{Zn}(\odot)$ and extinction (O) at $280 \mathrm{~nm}$ are shown.

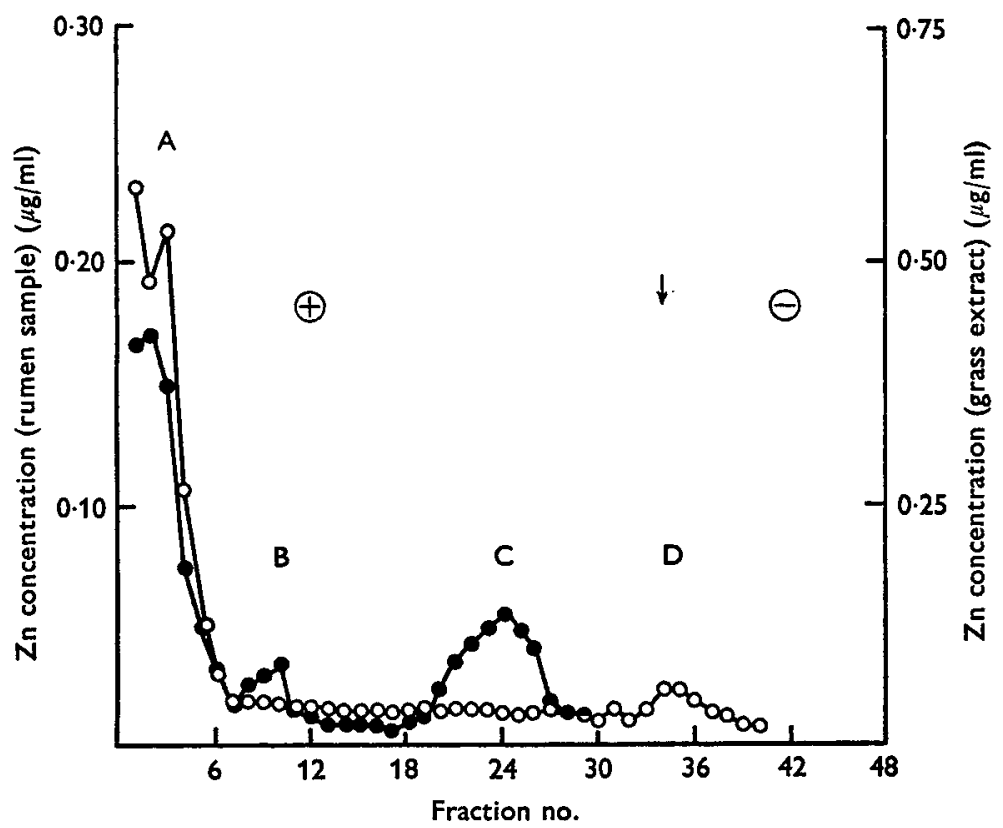

Fig. 5. Electrophoretic separation of supernatant fraction from rumen sample from sheep maintained on dried grass and of aqueous extract of dried grass at $\mathrm{pH} 6.5$. Concentrations of $\mathrm{Zn}$ in the rumen sample $(\mathrm{O})$ and grass extract $(\odot)$ and the positions of the introduction point $(\downarrow)$, anode $(\oplus)$ and cathode $(\Theta)$ are shown. For explanation of A-D, see p. 778 . 
(Fig. 5), one near-neutral (D) and the other (A) with a high anionic mobility similar to that of the $\mathrm{Zn}$ complex present in an aqueous extract of the dried grass. The other $\mathrm{Zn}$ complexes (B and C, Fig. 5) present in the grass extract were not detected in the rumen samples. Several similar cationic and anionic Mn-containing components were

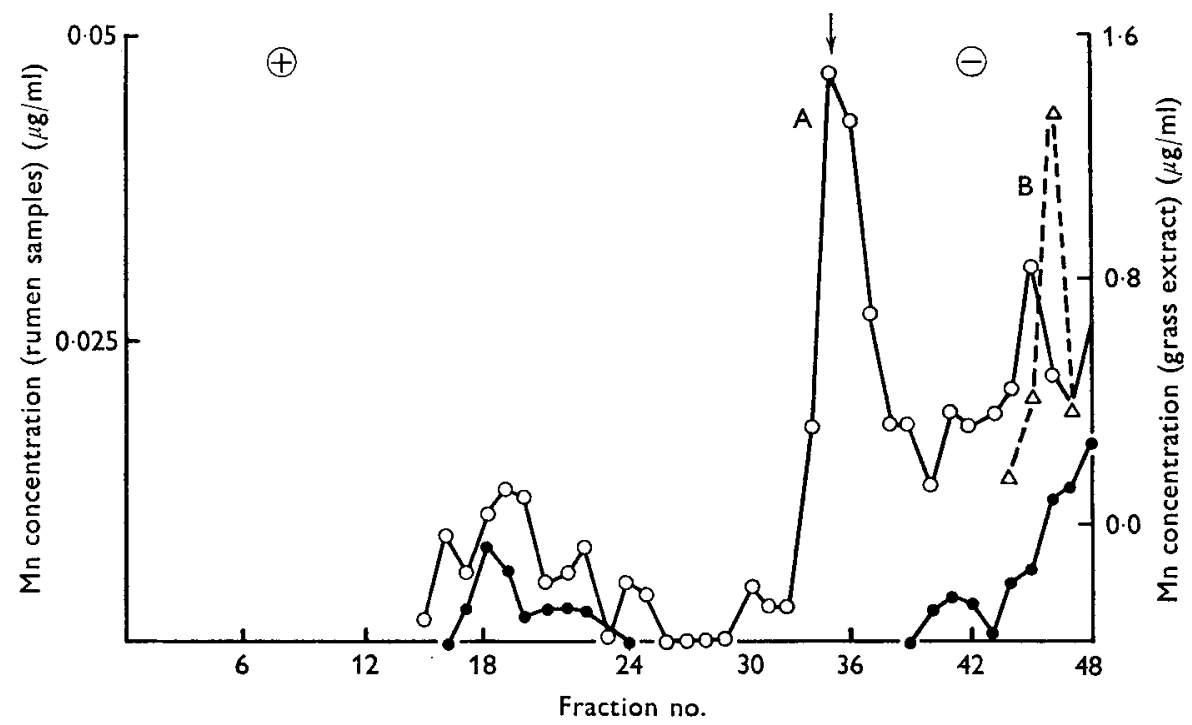

Fig. 6. Electrophoretic separation of aqueous extract of dried grass and of supernatant fractions of rumen samples collected from sheep maintained on dried grass before and after feeding. The Mn concentrations in the grass extract $(\Delta)$ and in the pre- $(\bullet)$ and postfeeding $(O)$ samples are shown. The sample introduction point $(\downarrow)$, anode $(\oplus)$ and cathode $(\Theta)$ are also indicated. For explanation of $A$ and $B$, see p. 779 .

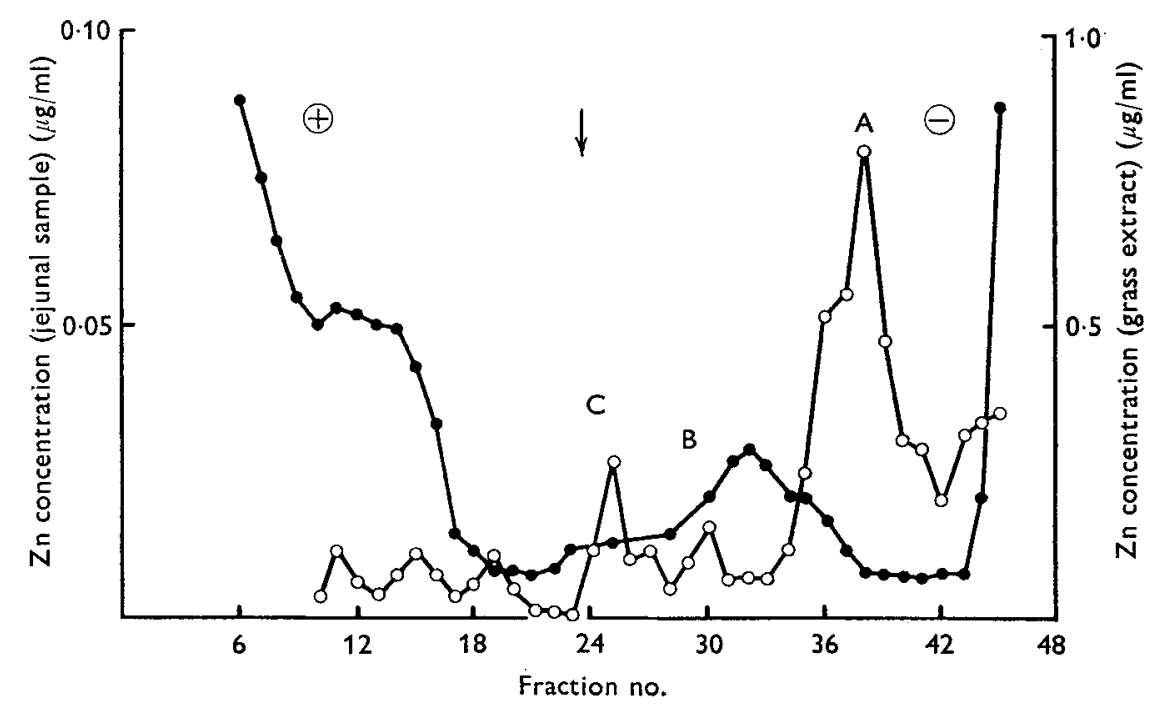

Fig. 7. Electrophoretic separation at $\mathrm{pH}_{4} .9$ of aqueous extract of dried grass and of supernatant fraction of sample from mid-jejunum of sheep maintained on dried grass. Zinc concentrations in the grass extract $(\odot)$ and jejunal sample $(O)$, the sample introduction point $(\downarrow)$, anode $(\oplus)$ and the cathode $(\ominus)$ are shown. For explanation of $A-C$, see p. 779. 
present in both post-feeding and pre-feeding samples (Fig. 6). A major neutral component (A) present in the former was, however, absent from the pre-feeding sample. Of the other complexes, one (B) had a mobility similar to that of the Mn complex present in an extract of dried grass.

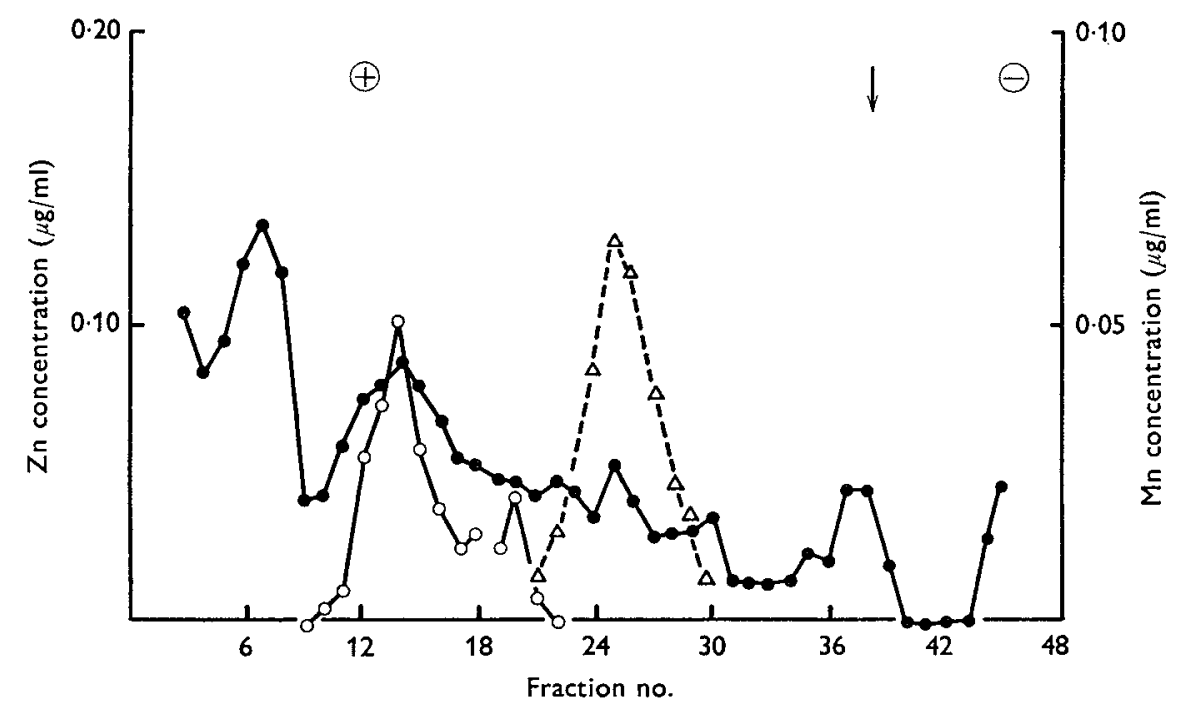

Fig. 8. Electrophoretic separation at $\mathrm{pH} 8 \cdot 2$ of aqueous extract of dried grass and of supernatant fraction of sample collected from the lower jejunum of sheep maintained on dried grass. Concentrations of $\mathrm{Zn}(\Theta)$ and of $\mathrm{Mn}(O)$ in the jejunal sample and of $\mathrm{Zn}(\triangle)$ in the grass extract, the sample introduction point $(\downarrow)$ and the anode $(\oplus)$ and cathode $(\ominus)$ are shown.

Electrophoretic examination in acetate buffer at $\mathrm{pH}_{4.9}$ of another sample collected from the upper jejunum gave the results shown in Fig. 7. The major cationic $\mathrm{Zn}$ complex (A) had a mobility about $75 \%$ of that of ionic $\mathrm{Zn}$. Although it was well separated from most of the u.v.-absorbing material present in the sample it did have $\lambda_{\max } 270 \mathrm{~nm}$. The minor anionic complexes and the cationic complex (B) could possibly have been derived from the similar complexes detected in an aqueous extract of dried grass (Fig. 7). A sample of sheep pancreatic juice was found to contain a major neutral $\mathrm{Zn}$ complex and it is possible that this corresponds to the neutral complex (C) found in the jejunal sample.

Examination of a sample collected from the lower end of the jejunum showed that in tris-acetate buffer at $\mathrm{pH} 8.2$ several anionic $\mathrm{Zn}$ complexes were present (Fig. 8). A minor complex had a mobility similar to that of the $\mathrm{Zn}$ complex detected in the aqueous extract of dried grass. Two anionic Mn complexes were detected in the sample collected from the lower jejunum (Fig. 8).

\section{DISCUSSION}

The results demonstrate that significant variations occur in the forms in which $\mathrm{Zn}$, $\mathrm{Mn}$ and $\mathrm{Cu}$ are present along the alimentary tract of sheep maintained on a dried grass ration. Progressive changes were found in the solubilities of the metals, with 
important differences being noted between the three metals. The solubilities of all three metals in the rumen were found to be extremely low. Although over $50 \%$ of the $\mathrm{Zn}, \mathrm{Mn}$ and $\mathrm{Cu}$ in the dried grass ration was found to be water-soluble and over $90 \%$ of the $\mathrm{Zn}$ and $\mathrm{Mn}$ was liberated on cellulolytic digestion of ryegrass (Bremner \& Knight, 1970), in the rumen only 5-10\% of the $\mathrm{Zn}$ and $\mathrm{Mn}$ and less than $20 \%$ of the $\mathrm{Cu}$ were in soluble form. Bosman (1964) has also noted the relatively low solubility of $\mathrm{Cu}$ in rumen samples.

The strength of binding of the metals to the insoluble rumen residue appeared to be in the order $\mathrm{Cu}>\mathrm{Zn}>\mathrm{Mn}$ on the basis of the extent of dissolution of the metals on treatment with acid or with EDTA (unpublished results). It seems possible, from the liberation of practically all the residual $\mathrm{Cu}$ but of less $\mathrm{Zn}$ and $\mathrm{Mn}$ on extraction of the rumen residue with SDS, that there exists a greater association of the $\mathrm{Cu}$ with the microbial material present in the rumen. These conclusions are strengthened by the finding that treatment with detergent had little effect on the solubilities of the metals in herbage. These studies are being continued in order to gain more insight into the nature of this possible association. It has been suggested previously from the results of differential centrifugation studies that such an association might exist (Mitchell \& Tosic, 1949; Mills, 1958). It is interesting to note in this connexion that the absorption of dietary $\mathrm{Cu}$ by germ-free rats may be more efficient than that of conventional rats (Dowdy, Herman \& Sauberlich, I969).

Of the three soluble anionic complexes of $\mathrm{Zn}$ which were detected in an aqueous extract of the dried grass on electrophoresis at $\mathrm{pH} 6.5$, only one was found in the supernatant fractions of the rumen samples, although there was, in addition, a minor neutral complex. The single cationic form of $\mathrm{Mn}$ detected in an aqueous extract of the dried grass was present in minor amounts in rumen samples collected both before and after feeding. The main difference between these samples lay in the presence of a major neutral complex of $\mathrm{Mn}$ in the post-feeding sample only. The large diurnal fluctuation noted in the concentration of soluble Mn may be associated with the disappearance of this complex. It does not seem from these results that there is a direct connexion between the dietary complexes and those detected in the rumen, but whether these differences are the result of absorption or of binding of the metals to the insoluble components of rumen contents is unknown. Rumen tissue appears to be capable of absorbing quite large amounts of $\mathrm{Zn}$ relative to other gut tissues (Arora, Hatfield, Garrigus, Lohman \& Doane, 1969). However, secretion of $\mathrm{Zn}$ into the rumen via the rumen epithelium and saliva seems to occur to only a slight extent (Weston \& Kastelic, 1967).

The large increases in the solubility of $\mathrm{Zn}$ and $\mathrm{Mn}$ on passage of the digesta into the abomasum must arise from the dissociation at low $\mathrm{pH}$ of the insoluble complexes present in the rumen. This seems especially probable as the same results were obtained on in vitro acidification of rumen samples. The reduction in the solubility of $\mathrm{Cu}$, however, is difficult to explain, although it also seems to be due to a $\mathrm{pH}$ effect. Although the results of the detergent extraction of the abomasal residues suggest that up to $55 \%$ of the total $\mathrm{Cu}$ could be associated with microbial matter in the abomasum, about $40 \%$ of the total $\mathrm{Cu}$ was still insoluble after treatment with detergent. If co-precipitation 
of $\mathrm{Cu}$ with macromolecular material occurred on acidification of the rumen samples (by passage into the abomasum or in vitro) the association must have been exceptionally stable to maintain the $\mathrm{Cu}$ in insoluble form at a $\mathrm{pH}$ as low as $\mathrm{I} \cdot 7$. Porter Johnston \& Porter ( 1962 ) have noted such affinity for $\mathrm{Cu}$ in only one protein, neonatal hepatic mitochondrocuprein. Most other $\mathrm{Cu}$-proteins appear to dissociate as the $\mathrm{pH}$ is lowered to $3-4$.

The importance of $\mathrm{pH}$ in controlling the solubility of the metals in the alimentary tract is shown by the close similarity between the soluble concentrations of the metals in the tract and those obtained on $\mathrm{pH}$ adjustment of abomasal samples, although other factors, such as absorption and secretion, must also affect both the concentrations and forms of the metals in the gut. It appears, from the similarity in the effects of $\mathrm{pH}$ adjustment on both untreated abomasal samples and supernatant fractions, that the decreases noted in the soluble concentrations of $\mathrm{Zn}$ and $\mathrm{Mn}$ were not due to adsorption of the metals on to other, insoluble, material present in the gastro-intestinal tract. The increases noted in the soluble concentrations of $\mathrm{Cu}$ and of $\mathrm{Zn}$ (above $\mathrm{pH}$ 6) (see Fig. I), however, must have been due to the liberation of the metals in macromolecular forms (for $\mathrm{Zn}$ at least) from this insoluble material. The availability of the metals along the alimentary tract cannot necessarily be equated directly with their solubilities, but it is to be expected that some correlation will exist. If this is so then it is surprising to note the discrepancy between the absorption rates of ${ }^{64} \mathrm{Cu}$ in ligated segments of rat intestine (stomach $>$ duodenum $>$ mid-section $>$ ileum) (Van Cam-

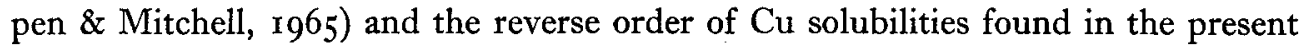
study. However, the use of ligated, or everted, segments of intestine can be criticized in so far as it is often unknown whether the intestinal mucosa is still functioning normally or whether the metal introduced has come into equilibrium with the metal already present in the intestine. If it has not, then the uptake of the ionic form of the metal in such preparations may not be relevant to the normal physiological situation.

In addition to the changes noted in the soluble concentrations of the metals along the alimentary tract, important differences were found in the soluble forms in which the metals were present. Zinc and Mn did not appear to be complexed in the acid environment of the abomasum, duodenum and upper jejunum. Any absorption from these regions of the alimentary tract will therefore presumably take place with the metals in ionic forms, at least in the initial stages of the absorptive process. It is well known that higher $\mathrm{pH}$ values generally favour complex formation, as the decreasing proton concentration limits the competition for the metal-binding sites on potential ligands. Thus, in samples collected from the mid-jejunal region several complexes of $\mathrm{Zn}$, mainly cationic and of low molecular weight, were present. It is possible that some of the $\mathrm{Zn}$ which was in a form with a higher molecular weight was associated with carboxypeptidases present in pancreatic juice, especially as the mobility of the major $\mathrm{Zn}$ component of pancreatic juice was the same as that of a minor jejunal $\mathrm{Zn}$ complex.

In samples collected from the lower jejunum and ileum the soluble forms in which the metals were present had changed again in so far as they were anionic and contained a greater proportion of $\mathrm{Zn}$ bound to macromolecular material. Part of the change in the electrophoretic behaviour of the $\mathrm{Zn}$ complexes was shown to be due to 
a $\mathrm{pH}$ effect, as the mid-jejunal sample discussed above was found to contain only anionic forms of $\mathrm{Zn}$ when examined at the higher $\mathrm{pH}$ value (not shown). Although it is probable that part of the increase in the molecular size of the complexes at high $\mathrm{pH}$ is a result of the hydrolysis and polymerization reactions of metal chelates (Chaberek \& Martell, I959), it is important to realize that in systems such as exist in the alimentary tract, where several potential ligands are present, even slight changes in $\mathrm{pH}$ can have an important effect on the relative contribution made by these ligands in the complexing of the metals present (Perrin, 1965).

Unfortunately, mainly because of the low concentrations involved, it has not so far been possible to identify the metal-binding species present in the different regions of the alimentary tract or to obtain information on the regions where the soluble $\mathrm{Cu}$ is complexed. It is to be expected that $\mathrm{Cu}$ complexes will be stable at lower $\mathrm{pH}$ values and therefore $\mathrm{Cu}$ absorption may involve complexed forms of the metals in the upper regions of the alimentary tract. Starcher (1969) has claimed that a $\mathrm{Cu}$-protein complex, of molecular weight around I0000, present in the duodenal mucosa of chicks, may be involved in the process of $\mathrm{Cu}$ absorption. Brown \& Rother (1963) have suggested that serine and glycine complexes may be involved in the absorption of iron by the rat. Davis, Luke \& Deller (I966) have claimed that an iron-binding protein, gastroferrin, present in gastric juice complexes with $\mathrm{Fe}$ to make it non-available to the intestinal mucosa of normal animals.

The requirements of ruminants for trace elements have often been found to be less on purified diets than on conventional diets. Although it has been suggested that this is due, at least in some instances, to the existence of the trace metals in the conventional diet in the form of non-available complexes, it appears likely from the results of this and the earlier paper (Bremner \& Knight, 1970) that the complexes of the trace elements $\mathrm{Zn}$ and $\mathrm{Mn}$ present in grass are insufficiently stable for them to exist intact in the digestive tract of sheep. It is hoped, however, to make a similar study of the trace metals in the gastro-intestinal tract of sheep maintained on a purified diet in order to find if differences do occur in the complexed forms of the metals and if these can be related in any way to the differences in availability.

I wish to thank Dr C. F. Mills for his constant advice and encouragement while this work was being done. The surgical operations on the sheep were kindly carried out by Dr R. N. B. Kay. The technical assistance of Mr G. C. Smith is gratefully acknowledged.

\section{REFERENCES}

Arora, S. P., Hatfield, E. E., Garrigus, U. S., Lohman, T. G. \& Doane, B. B. (1 969). f. Nutr. 97, 25. Bosman, M. S. M. (1964). Faarb. Inst. biol. scheik. Onderz. LandbGewass., 1964, p. 125.

Bremner, I. \& Knight, A. H. (1970). Br. F. Nutr. 24, 279.

Brown, E. B. \& Rother, M. L. (1963). F. Lab. clin. Med. 62, 357.

Chaberek, S. \& Martell, A. E. (1959). In Organic Sequestering Agents. New York: John Wiley and Sons Inc.

Davis, P. S., Luke, C. G. \& Deller, D. J. (I966). Lancet ii, I43I.

Dowdy, R. P., Herman, Y. F. \& Sauberlich, H. E. (1969). Proc. Soc. exp. Biol. Med. 130, I294.

Dowdy, R. P. \& Matrone, G. (1968a). F. Nutr. 95, 191.

Dowdy, R. P. \& Matrone, G. (1968b). F. Nutr. 95, 197. 
Kroe, D. J., Kaufman, N., Klavins, J. V. \& Kinney, T. D. (1966). Am. F. Physiol. 211, 4 I4. Mason, V. C. (1 969). F. agric. Sci., Camb. 73, 99.

Mitchell, R. L. \& Tosic, J. (1949). F. gen. Microbiol. 3, xvi.

Mills, C. F. (1958). Soil Sci. 85, 100.

Perrin, D. D. (1965). Nature, Lond. 206, r 70.

Porter, H., Johnston, J. \& Porter, E. M. (I962). Biochim. biophys. Acta 65, 66.

Saltman, P. (I965). F. chem. Educ. 42, 682 .

Starcher, B. C. (1969). F. Nutr. 97, 32 г.

Storry, J. E. (196r). F. agric. Sci., Camb. 57, 97.

Topps, J. H., Kay, R. N. B. \& Goodall, E. D. (1968). Br. F. Nutr. 22, 261.

Van Campen, D. R. \& Mitchell, E. A. (1965). F. Nutr. 86, 120.

Weston, R. H. \& Kastelic, J. (1967). Aust. F. biol. Sci. 20, 975. 